\title{
Impact of Serum Lipid on Breast Cancer Recurrence
}

\author{
Sung Mi Jung ${ }^{1,+}{ }^{\mathbb{C}}$, Danbee Kang ${ }^{2,3,+}$, Eliseo Guallar ${ }^{2,4,5}$, Jonghan $\mathrm{Yu}^{1}{ }^{1}$, Jeong Eon Lee ${ }^{1}$, \\ Seok Won Kim ${ }^{1}$, Seok Jin Nam ${ }^{1}$, Juhee Cho ${ }^{2,3,4, *}$ and Se Kyung Lee ${ }^{1, *}$
}

1 Division of Breast Surgery, Department of Surgery, Samsung Medical Center, Sungkyunkwan University School of Medicine, Seoul 06351, Korea; happy12pm@hanmail.net (S.M.J.); jonghan.yu@samsung.com (J.Y.); jeongeon.lee@samsung.com (J.E.L.); seokwon1.kim@samsung.com (S.W.K.); seokjin.nam@samsung.com (S.J.N.)

2 Center for Clinical Epidemiology, Samsung Medical Center, Sungkyunkwan University School of Medicine, 81 Irwon-ro, Gangnam-gu, Seoul 06351, Korea; cce.smc@samsung.com (D.K.); eliseo.guallar@samsung.com (E.G.)

3 Department of Clinical Research Design and Evaluation, SAIHST, Sungkyunkwan University, Seoul 06351, Korea

4 Department of Epidemiology, Johns Hopkins Bloomberg School of Public Health, Baltimore, MD 21205, USA

5 Department of Health, Behavior and Society, Johns Hopkins Bloomberg School of Public Health, Baltimore, MD 21205, USA

* Correspondence: jcho@skku.edu (J.C.); sekyung.lee@samsung.com (S.K.L.); Tel.: +82-2-3410-3478 (S.K.L.); Fax: +82-2-3410-6982 (S.K.L.)

+ These authors contributed equally to this work.

Received: 29 July 2020; Accepted: 26 August 2020; Published: 2 September 2020

\begin{abstract}
The association between serum lipid level and prognosis of breast cancer is controversial. The purpose of this study was to evaluate the impact of serum lipid level in breast cancer recurrence. We analyzed a total of 4190 patients with operable breast cancer who had baseline serum lipid profiles; total cholesterol (TC), triglycerides (TG), low density lipoprotein-cholesterol (LDL-C), high density lipoprotein-cholesterol (HDL-C), apolipoprotein A-1, and apolipoprotein B. Recurrence-free survival is defined as the elapsed time from the date of curative surgery to the detection of any recurrence, and recurrence includes locoregional recurrence, distant metastasis, or both local and distant metastasis. Cox-proportional hazard analysis was used to estimate hazard ratios with $95 \%$ confidence intervals (CI) for study outcomes comparing the three lowest quartiles of each lipid parameter to the highest quartile adjusting for age, body mass index (BMI), and pathologic stage, estrogen receptor (ER), progesterone receptor (PR), comorbidities (hypertension, diabetes, or vascular event) at time of breast cancer diagnosis. Patients with dyslipidemia (high bad cholesterol and low good cholesterol level) had worse prognostic factors (i.e., negative hormone receptor status, positive human epidermal growth factor receptor 2 (HER2) expression, higher nuclear grade). After adjusting for these poor prognostic factors, the patients with dyslipidemia showed good prognosis for breast cancer recurrence. Our study showed that baseline high lipid level could be a good prognostic factor of breast cancer. This study indicates that desirable changes in lipid profile for cardiovascular disease risk are not always beneficial for patients with breast cancer. However, as proper control of lipid level has advantages for cardiovascular disease, these findings require careful interpretation.
\end{abstract}

Keywords: Breast neoplasms; cholesterol; lipids; survival

\section{Introduction}

Breast cancer is not only the most common type of cancer in women [1], but also a representative cancer with a good prognosis. However, despite the fact that most breast cancers have a good prognosis, 
some still show bad progress such as recurrence and metastasis [2,3]. Breast cancer is a complex, heterogeneous disease with various biological characteristics, therefore, each breast cancer patient may have different responses to treatment [4]. Efforts have been made to find prognostic factors of breast cancer. Known major prognostic factors found so far include TNM stage, estrogen receptor (ER), progesterone receptor (PR), and human epidermal growth factor receptor 2 (HER2), however, most of these prognostic factors were for the character of the tumor itself. In addition, several studies have also examined the new prognostic factors related to individual characteristics, such as lifestyle (e.g., alcohol consumption, soy ingestion, active smoking, and obesity). Alcohol consumption increases the risk of breast cancer, and reducing alcohol consumption decreases the incidence of breast cancer among women who consume alcohol regularly [5]. Several studies have reported that soy consumption may protect against breast cancer, while other studies have shown that isoflavone, the major component of soy, enhance the proliferation of breast cancer cells [6,7]. Smoking was associated with increased breast cancer risk relative to all non-smokers [8], and being overweight is also related to a higher risk of mortality [9-11].

Among them, the role of blood cholesterol and statin on breast cancer prognosis was also suggested. Cholesterol is an essential structural component of the cell membranes which helps maintain both membrane structural integrity and fluidity. Cholesterol is also implicated in cellular signaling pathways through assisting in the formation of lipid rafts in the plasma membrane, which brings receptor proteins in close proximity with high concentrations of second messenger molecules [12]. These key cellular signaling is closely associated with malignant transformation of cells because of their role in organization of the cytoskeleton, cell migration, and angiogenesis [12-14]. In addition to this, within cells, cholesterol also serves as a precursor for the biosynthesis of steroid hormones, including the sex hormones progesterone, estrogens, and their derivatives which is important risk factors in breast cancer development. Because of the possibility of causal relations between cholesterol and breast cancer, the clinical role of cholesterol in cancer development and recurrence has been suggested. However, studies for the relation of cholesterol and breast cancer have not been concluded.

While dyslipidemia is common among breast cancer patients, the previous reports in the influence of dyslipidemia on breast cancer is inconsistent. Some studies found that the elevated levels of cholesterol were negative effects in breast cancer patients [15-19], otherwise, cholesterol level is not associated with the risk of breast cancer [20-23], and even showed an inverse correlation which is elevated serum levels of triglycerides (TG) may be associated with a reduced breast cancer risk [24]. In the field of lipoproteins which are responsible for the cholesterol transportation, studies are also inconclusive. Regarding high density lipoprotein-cholesterol (HDL-C), some authors showed a positive association between low HDL-C levels and increased breast cancer risk [21,25-29]; while others reported no association [30], and some even report a negative correlation between low HDL-C and breast cancer [31]. The study for low density lipoprotein-cholesterol (LDL-C) showed no association with breast cancer risk [21,23]. TG levels were no associated with risk of breast cancer [20,28], however, others showed an inverse correlation between high serum TG [32]. Therefore, this study aimed to evaluate the impact of serum lipid levels on breast cancer recurrence.

\section{Materials and Methods}

\subsection{Study Population}

The study population was composed of patients who underwent breast cancer surgery at Samsung Medical Center Breast Cancer Center in Seoul, South Korea, from 1 January 2008 to 6 March 2014 $(n=8362)$. We excluded patients who were male $(n=40)$, those who received neoadjuvant therapy $(n=561)$, those with ductal carcinoma in situ (DCIS; $n=964)$ or stage $4(n=17)$ disease, and those with baseline dyslipidemia $(n=521)$, phyllodes tumor $(n=25)$, sarcoma $(n=4)$, metastatic cancer $(n=16)$, or malignancy of unknown origin $(n=4)$. Since the aim of the study was to evaluate the association between lipid profile at the time of diagnosis and five-year recurrence, we further excluded patients 
who did not have complete lipid profiles at the time of diagnosis $(n=2081)$ or with missing data for others $(n=2)$. Since study participants could have more than one exclusion criteria, the final sample size was 4190 and average follow up duration was 73.83 months (Figure 1). The Institutional Review Board of the Samsung Medical Center, Seoul Korea (IRB file no.2015-11-078) approved this study and waived the requirement for informed consent as we used only de-identified data routinely collected during routine cancer care. This article does not contain any studies animals performed by any of the authors. This study was performed in accordance with the Declaration of Helsinki.

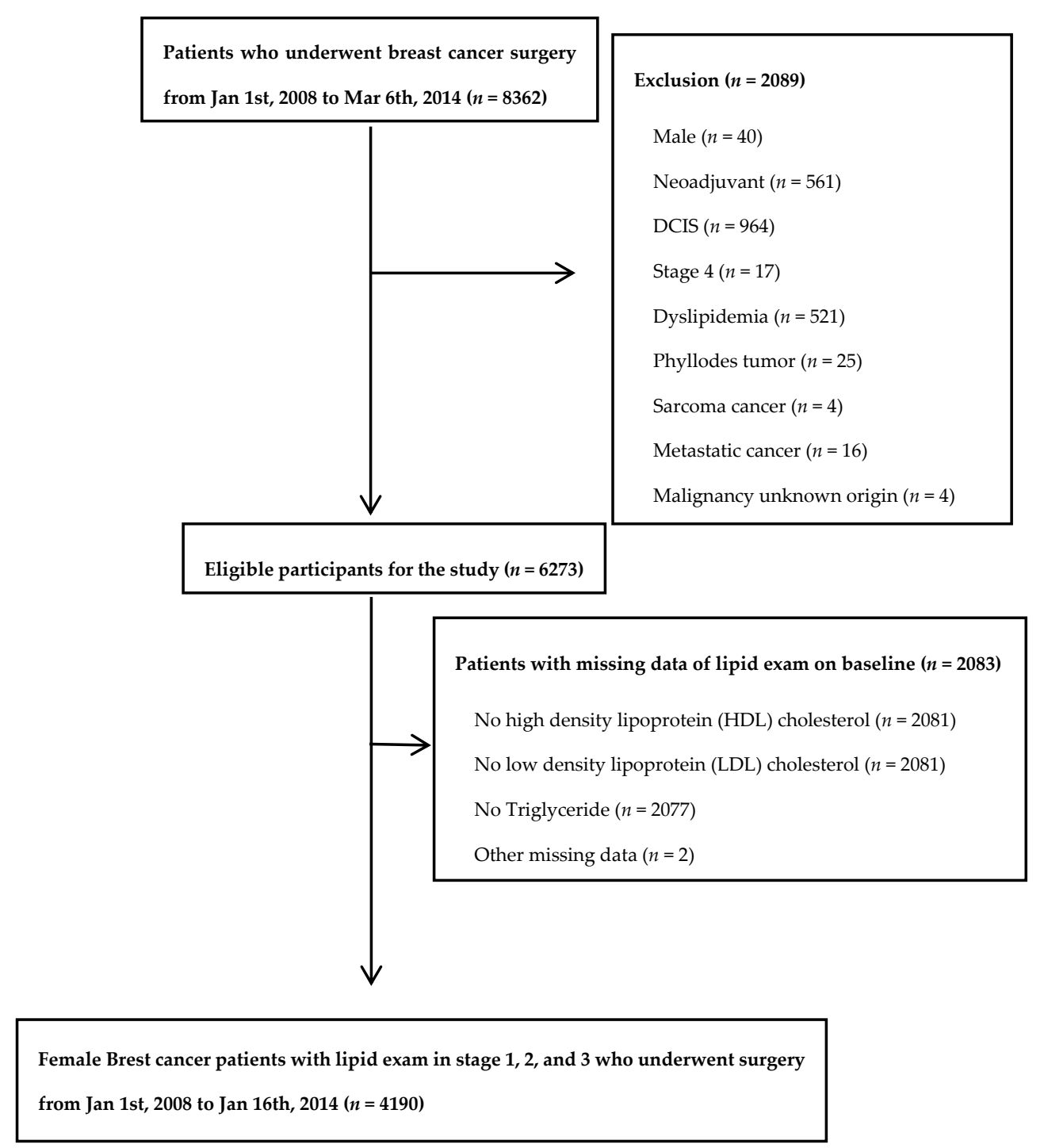

Figure 1. Flow chart of population.

\subsection{Measurements}

The baseline and clinicopathologic characteristics including demographic factors, pathologic findings, and perioperative treatment of breast cancer patients were collected from the electronic medical records. Age was collected at the time of breast cancer diagnosis and body mass index (BMI) was defined as the weight divided by the square of the body height at the time of breast cancer surgery. Menopause status was one of the following conditions; prior bilateral oophorectomy status, age over 60 years-old and amenorrhea for 12 or more months in patients under 60 years of age. Comorbidity for hypertension, diabetes, and vascular events were investigated.

Pathologic stage was based on American Joint Committee on Cancer 8th Edition [33]. Two experienced pathologists reviewed and determined characteristics of primary tumor based on size, axillary nodal status, 
resection margin and the status of receptors (ER, PR, and HER2) according to immunohistochemical (IHC) staining. Detailed information on surgery, adjuvant chemotherapy, radiotherapy, and hormone therapy were obtained from electronic medical records.

Participants were asked to fast for $12 \mathrm{~h}$ and avoid smoking on the morning of the examination. All lipids and lipoproteins were measured using a Hitachi 7600 Modular Dp-110 auto-analyzer (Hitachi, Tokyo, Japan) and included enzymatic colorimetric tests (total cholesterol (TC) and TG), homogeneous enzymatic colorimetric tests (LDL-C and HDL-C), and immunoturbidimetric assays (apolipoprotein A-1 (ApoA-1) and apolipoprotein B (ApoB)).

In addition, we investigated recurrence through disease free survival, and recurrence-free survival is defined as the elapsed time from the date of curative surgery to the detection of any recurrence. Recurrence includes locoregional recurrence, distant metastasis, or both local and distant metastasis. Time to recurrence is defined as the interval between the date of surgical resection and the date of the first recurrence of the last follow-up. Overall survival is defined as the duration from the date of curative surgery until death by any causes.

\subsection{Statistical Analysis}

Cox-proportional hazard analysis was used to estimate hazard ratios with $95 \%$ confidence intervals (CI) for study outcomes comparing the three lowest quartiles of each lipid parameter to the highest quartile. To consider potential confounding factors at baseline, we adjusted for age, BMI, pathologic stage, ER, PR and comorbidities (hypertension, diabetes, or vascular event) at time of breast cancer diagnosis. To evaluate predictive accuracies of risk prediction models, we used Harrell's C-index which is the most widely used measure of predictive accuracy for survival models [34]. The values over 0.7 indicate a good model. All reported $p$-values were two-sided and the significance level was set at 0.05. All analysis was performed using SAS version 9.4 (SAS Institute, Inc., Cary, NC, USA) and STATA version 13 (StataCorp LP, College Station, TX, USA).

\section{Results}

\subsection{Patients Characteristics}

The mean age of study patients was 51.7 years and the mean BMI was $23.6 \mathrm{~kg} / \mathrm{m}^{2}$. Overall, $72.2 \%$ of patients underwent breast-conserving surgery, and $75.3 \%, 69.1 \%$, and $20.1 \%$ of patients were ER positive, PR positive, and HER2 positive, respectively. The percentage of patients on pathologic stage I, II, and III were $48.9 \%, 40.1 \%$, and $11.0 \%$, respectively. Lymphovascular invasion was present in $27.4 \%$ of patients, and $21.8 \%$ had multiple tumors. Regarding nuclear grade, $20.2 \%, 46.4 \%$, and $33.3 \%$ of patients had low, intermediate, and high grade tumors, respectively (Table 1).

Table 1. Patients characteristics.

\begin{tabular}{lc}
\hline Age, mean (SD) & $51.7(9.8)$ \\
\hline BMI, mean (SD) & $23.6(3.2)$ \\
\hline Blood lab, mean (SD) & \\
Total cholesterol (110-240) (mg/dL) & $193.3(33.7)$ \\
Triglyceride (50-200) (mg/dL) & $102.8(61.4)$ \\
HDL cholesterol (45-65) (mg/dL) & $59.9(14.8)$ \\
LDL cholesterol (40-130) (mg/dL) & $119.4(29.8)$ \\
TG/HDL & $2.0(1.7)$ \\
Non-HDL cholesterol & $133.4(33.7)$ \\
\hline
\end{tabular}


Table 1. Cont.

\begin{tabular}{|c|c|}
\hline & Overall $(N=4190)$ \\
\hline & $\mathbf{N}(\%)$ \\
\hline \multicolumn{2}{|l|}{ Menopausal status } \\
\hline Yes & $2217(52.9)$ \\
\hline No & $1962(46.8)$ \\
\hline Unknown & $11(0.3)$ \\
\hline \multicolumn{2}{|c|}{ Comorbidity $(n=2946) *$} \\
\hline No & $2310(78.4)$ \\
\hline Yes & $636(21.6)$ \\
\hline \multicolumn{2}{|c|}{ Surgery type $(n=4188)$} \\
\hline >Mastectomy & $1166(27.8)$ \\
\hline BCS & $3022(72.2)$ \\
\hline \multicolumn{2}{|l|}{ Stage } \\
\hline I & $2050(48.9)$ \\
\hline II & $1679(40.1)$ \\
\hline III & $461(11.0)$ \\
\hline \multicolumn{2}{|l|}{ ER } \\
\hline Positive & $3155(75.3)$ \\
\hline Negative & $1032(24.6)$ \\
\hline Unknown & $3(0.1)$ \\
\hline \multicolumn{2}{|l|}{ PR } \\
\hline Positive & $2894(69.1)$ \\
\hline Negative & $1293(30.9)$ \\
\hline Unknown & $3(0.1)$ \\
\hline \multicolumn{2}{|l|}{ HER2 } \\
\hline Positive & $842(20.1)$ \\
\hline Negative & $3275(78.2)$ \\
\hline Unknown & $73(1.7)$ \\
\hline \multicolumn{2}{|l|}{ Subtype } \\
\hline Luminal A & $2737(65.3)$ \\
\hline Luminal B & $406(9.7)$ \\
\hline HER2 type & $436(10.4)$ \\
\hline TNBC & $538(12.8)$ \\
\hline Unknown & $73(1.7)$ \\
\hline \multicolumn{2}{|l|}{ LVI } \\
\hline No & $3018(72.0)$ \\
\hline Yes & $1149(27.4)$ \\
\hline Unknown & $23(0.6)$ \\
\hline \multicolumn{2}{|l|}{ Multiplicity } \\
\hline No & $3274(78.1)$ \\
\hline Yes & $913(21.8)$ \\
\hline Unknown & $3(0.1)$ \\
\hline \multicolumn{2}{|l|}{ Nuclear grade } \\
\hline Low & $847(20.2)$ \\
\hline Intermediate & $1942(46.4)$ \\
\hline High & $1393(33.3)$ \\
\hline Unknown & $8(0.2)$ \\
\hline \multicolumn{2}{|l|}{ Chemotherapy } \\
\hline No & $1532(36.6)$ \\
\hline Yes & $2586(61.7)$ \\
\hline Unknown & $72(1.7)$ \\
\hline \multicolumn{2}{|l|}{ Radiotherapy } \\
\hline No & $882(21.1)$ \\
\hline Yes & $3205(76.5)$ \\
\hline Unknown & $103(2.5)$ \\
\hline
\end{tabular}


Table 1. Cont.

\begin{tabular}{cc}
\hline & Overall $(\boldsymbol{N}=\mathbf{4 1 9 0 )}$ \\
\cline { 2 - 2 } & $\mathbf{N}(\mathbf{\%})$ \\
\hline Hormone therapy & $781(18.6)$ \\
No & $3409(81.4)$ \\
Yes & $1439(34.3)$ \\
AI $\ddagger$ & $1887(45.0)$ \\
SERM $\S$ &
\end{tabular}

* Comorbidity included hypertension, diabetes, and vascular events and it was measured from 2009 year. $\ddagger$ AI (aromatase inhibitor) is Anastrozole, Exemestsane, Letrozole, and Arimidex. § SERM is Tamoxifen or Toremifen. BCS: breast-conserving surgery; BMI: body mass index; ER: estrogen receptor; HDL: high density lipoprotein; HER2: human epidermal growth factor receptor 2; LDL: low density lipoprotein; LVI: lymphovascular invasion; PR: progesterone receptor; SD: standard deviation; TG: triglyceride; TNBC: triple negative breast cancer.

High levels of TC, LDL-C, and TG and low levels of HDL-C were clearly associated with older age, menopause, and high BMI. Higher levels of TC, LDL-C, and TG were statistically associated with negative expression of ER and PR, positive HER2, non-luminal subtype, and single lesion. Low HDL-C level was associated with negative ER expression alone. The tumors of patients with high LDL-C and low HDL-C showed a higher nuclear grade. Patients with high TG and low HDL-C level had higher disease stage, whereas TC and LDL-C level were not associated with stage (Tables S1-S4).

There was no association between basal levels of serum lipid at the time of surgery and severity of the disease. When we calculated correlation between pathology stage which is severity of the disease and each blood marker, the correlation values were $0.01,-0.09,0.04,0.03,0.04$, and 0.05 in TC, LDL-C, HDL-C, TG, TG/HDL, and Non-HDL cholesterol, respectively. While some $p$-values were statistically significant, the magnitude is too small to tell the correlation (Figure 2).
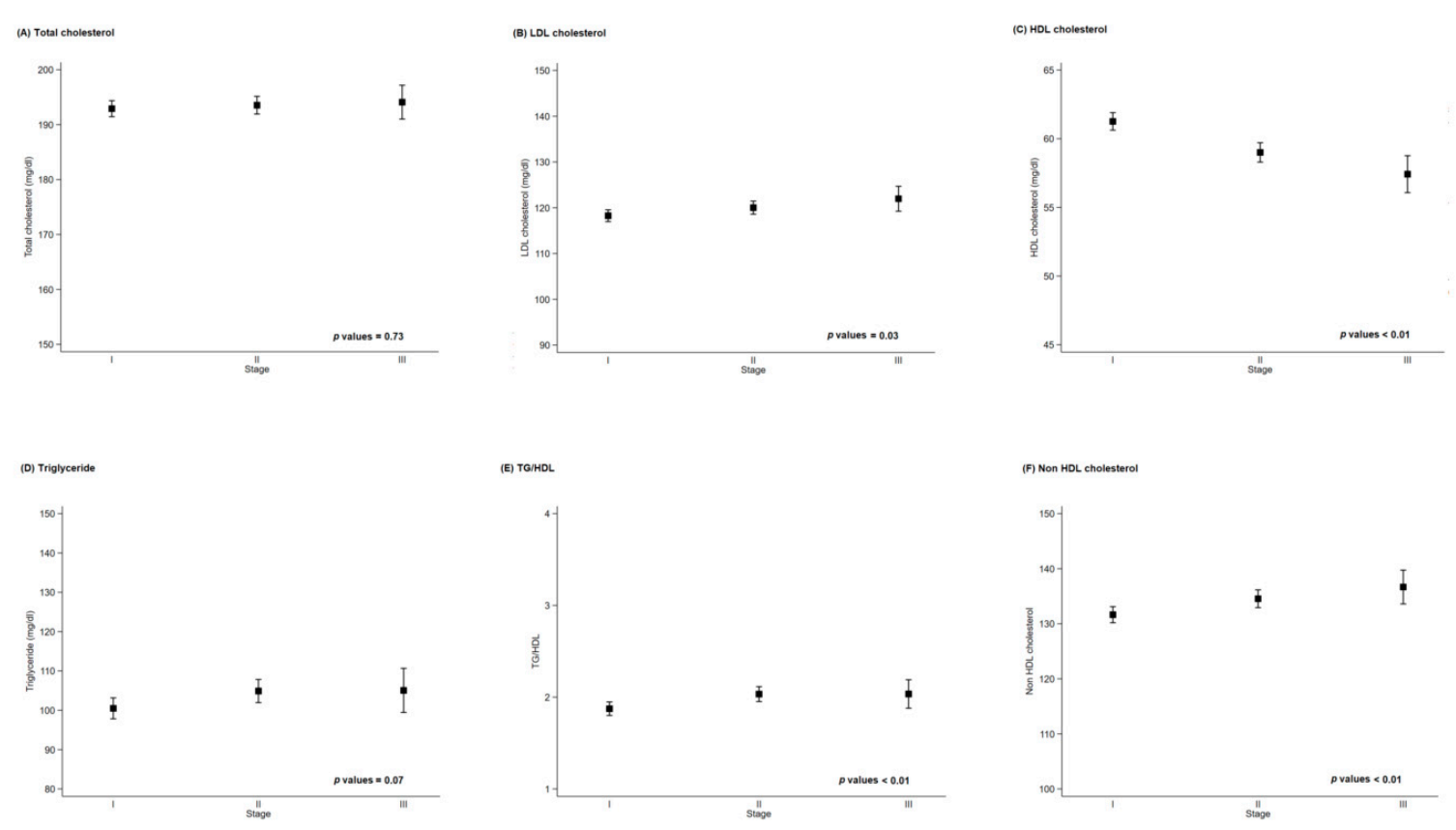

Figure 2. Baseline lipid marker by disease severity. HDL: high density lipoprotein; LDL: low density lipoprotein; TG: triglycerides.

\subsection{Prognostic Role of Lipid Profile with Regard to Disease Recurrence in Breast Cancer Patients}

The median follow-up period for recurrence was 22.28 (1.08-70.72) months. There were 125 recurrence events at the time of analysis (125/4190; 2.98\%). As shown in Table 2, in the univariable analysis (crude hazard ratio in Table 2), the upper normal range (quartile III) of LDL-C level showed a 
1.87-times (95\% CI: 1.08 to 3.25) higher risk of recurrence compared to a high level of LDL-C (quartile IV). For TG level, the abnormally low group (quartile I) exhibited a 1.87-times (95\% CI: 1.07 to 3.28) higher risk of recurrence compared to the abnormally high TG group (quartile IV). Conversely, a low level of HDL-C (quartile I) showed a protective effect on recurrence.

Table 2. Prognostic role of lipid profile with regard to disease recurrence.

\begin{tabular}{|c|c|c|c|c|c|}
\hline & \multirow{2}{*}{$\begin{array}{l}\text { Patients with } \\
\text { Events }\end{array}$} & \multicolumn{2}{|c|}{ Crude } & \multicolumn{2}{|c|}{ Adjusted } \\
\hline & & $\begin{array}{l}\text { Hazard Ratio } \\
\quad(95 \% \text { CI })\end{array}$ & $p$-Value & $\begin{array}{l}\text { Hazard Ratio } \\
\text { (95\% CI) }\end{array}$ & $p$-Value \\
\hline \multicolumn{6}{|c|}{ Total cholesterol } \\
\hline Quartile I & 34 & $1.49(0.89,2.48)$ & 0.13 & $1.34(0.78,2.30)$ & 0.28 \\
\hline Quartile II & 29 & $1.18(0.70,2.01)$ & 0.54 & $1.14(0.66,1.96)$ & 0.63 \\
\hline Quartile III & 36 & $1.60(0.96,2.65)$ & 0.07 & $1.47(0.88,2.45)$ & 0.14 \\
\hline Quartile IV & 26 & \multicolumn{2}{|c|}{ Reference } & \multicolumn{2}{|c|}{ Reference } \\
\hline \multicolumn{6}{|c|}{ LDL cholesterol } \\
\hline Quartile I & 33 & $1.68(0.97,2.90)$ & 0.06 & $1.71(0.96,3.06)$ & 0.07 \\
\hline Quartile II & 35 & $1.72(0.99,2.95)$ & 0.05 & $1.62(0.92,2.83)$ & 0.09 \\
\hline Quartile III & 36 & $1.88(1.09,3.22)$ & 0.02 & $1.88(1.09,3.27)$ & 0.02 \\
\hline Quartile IV & 21 & \multicolumn{2}{|c|}{ Reference } & \multicolumn{2}{|c|}{ Reference } \\
\hline \multicolumn{6}{|c|}{ HDL cholesterol } \\
\hline Quartile I & 33 & $0.58(0.37,0.93)$ & 0.02 & $0.54(0.33,0.88)$ & 0.01 \\
\hline Quartile II & 33 & $0.65(0.41,1.04)$ & 0.07 & $0.59(0.37,0.96)$ & 0.03 \\
\hline Quartile III & 20 & $0.43(0.25,0.75)$ & $<0.001$ & $0.45(0.26,0.77)$ & $<0.01$ \\
\hline Quartile IV & 39 & \multicolumn{2}{|c|}{ Reference } & \multicolumn{2}{|c|}{ Reference } \\
\hline \multicolumn{6}{|c|}{ Triglyceride } \\
\hline Quartile I & 34 & $1.75(0.05,2.93)$ & 0.03 & $1.88(1.07,3.29)$ & 0.03 \\
\hline Quartile II & 34 & $1.55(0.93,2.59)$ & 0.09 & $1.66(0.97,2.82)$ & 0.06 \\
\hline Quartile III & 31 & $1.36(0.81,2.29)$ & 0.25 & $1.32(0.78,2.25)$ & 0.31 \\
\hline Quartile IV & 26 & \multicolumn{2}{|c|}{ Reference } & \multicolumn{2}{|c|}{ Reference } \\
\hline \multicolumn{6}{|c|}{ TG/HDL } \\
\hline Quartile I & 32 & $1.59(0.95,2.64)$ & 0.08 & $1.82(1.04,3.21)$ & 0.04 \\
\hline Quartile II & 30 & $1.40(0.83,2.35)$ & 0.21 & $1.57(0.91,2.73)$ & 0.11 \\
\hline Quartile III & 35 & $1.43(0.87,2.35)$ & 0.16 & $1.45(0.87,2.42)$ & 0.16 \\
\hline Quartile IV & 28 & \multicolumn{2}{|c|}{ Reference } & \multicolumn{2}{|c|}{ Reference } \\
\hline \multicolumn{6}{|c|}{ Non-HDL cholesterol } \\
\hline Quartile I & 31 & $1.41(0.85,2.35)$ & 0.19 & $1.53(0.89,2.66)$ & 0.13 \\
\hline Quartile II & 32 & $1.37(0.83,2.28)$ & 0.22 & $1.45(0.85,2.48)$ & 0.17 \\
\hline Quartile III & 34 & $1.47(0.89,2.43)$ & 0.13 & $1.55(0.92,2.61)$ & 0.10 \\
\hline Quartile IV & 28 & \multicolumn{2}{|c|}{ Reference } & \multicolumn{2}{|c|}{ Reference } \\
\hline
\end{tabular}

Total cholesterol (mg/dL): $Q_{1}=170, Q_{2}=191, Q_{3}=215 ;$ LDL cholesterol (mg/dL): $Q_{1}=98, Q_{2}=118, Q_{3}=139$; HDL cholesterol (mg/dl): $Q_{1}=49, Q_{2}=59, Q_{3}=69$; Triglyceride $(\mathrm{mg} / \mathrm{dl}): Q_{1}=63, Q_{2}=87, Q_{3}=123$; TG/HDL: $Q_{1}=0.97, Q_{2}=1.47, Q_{3}=2.33$ Non-HDL cholesterol: $Q_{1}=109, Q_{2}=132, Q_{3}=156$; Adjusted for adjusted for age, body mass index (BMI), pathologic stage, estrogen receptor (ER), progesterone receptor (PR), and comorbidities (hypertension, diabetes, or vascular event) at time of breast cancer diagnosis; CI: confidence interval; HDL: high density lipoprotein; LDL: low density lipoprotein; TG: triglycerides.

The C-index of the models for recurrence free survival at five years were $0.7568,0.7573,0.7489$, $0.7613,0.7545$, and 0.7595 in TC, LDL-C, HDL-C, TG, TG/HDL and Non-HDL cholesterol, respectively. After adjustment for several confounding factors that had a high correlation with lipid profile and breast cancer prognosis, the prognostic effects of LDL-C, TG, and HDL-C on recurrence were maintained. In adjusted model, a high ratio of TG to HDL-C that could predict insulin resistance [35] and/or the development of coronary disease [36] showed a protective effect compared to a very low ratio.

Interestingly, as shown in Figures 3 and 4, patients with a high level of bad lipids (LDL-C, TG, and TG/HDL) and low level of good lipid (HDL-C) generally displayed a good prognosis for breast 
cancer recurrence. There were patients with normal lipid level among patients with recurrence, and the patients with normal level of HDL $(52.8 \%)$ or LDL cholesterol $(70.4 \%)$ were relatively lower than patients with normal level of TC $(90.4 \%)$ or TG $(83.2 \%)$.

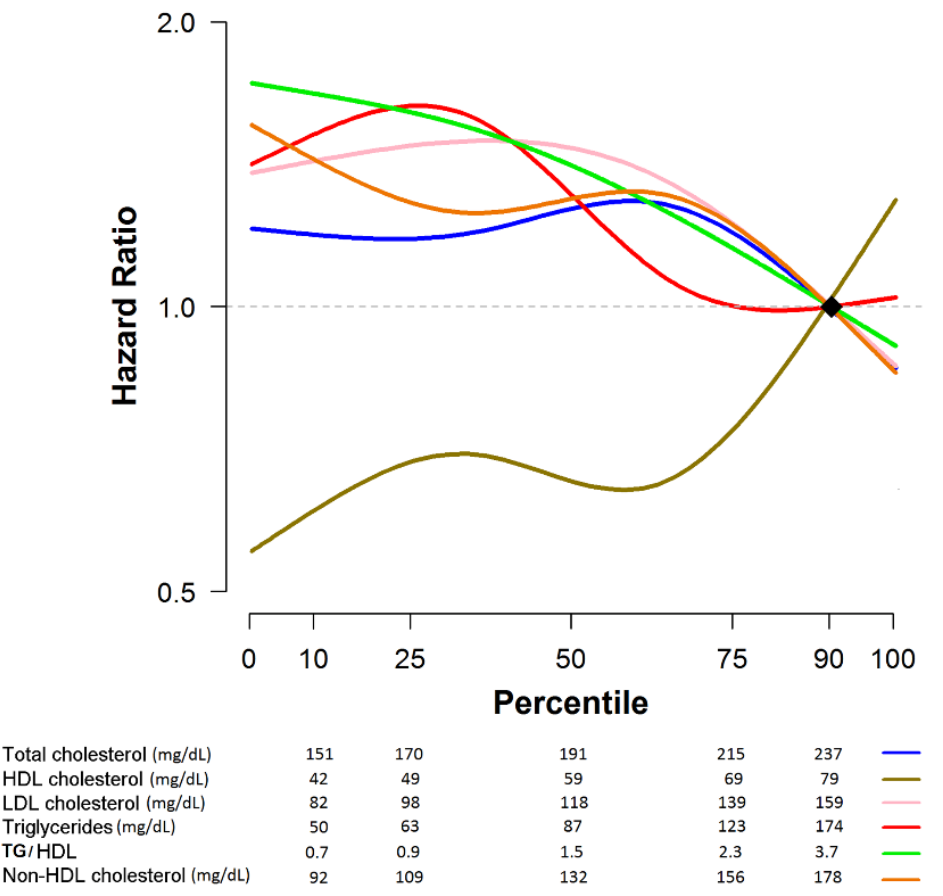

Figure 3. Hazard ratio by lipid exam score. HDL: high density lipoprotein; LDL: low density lipoprotein; TG: total cholesterol.
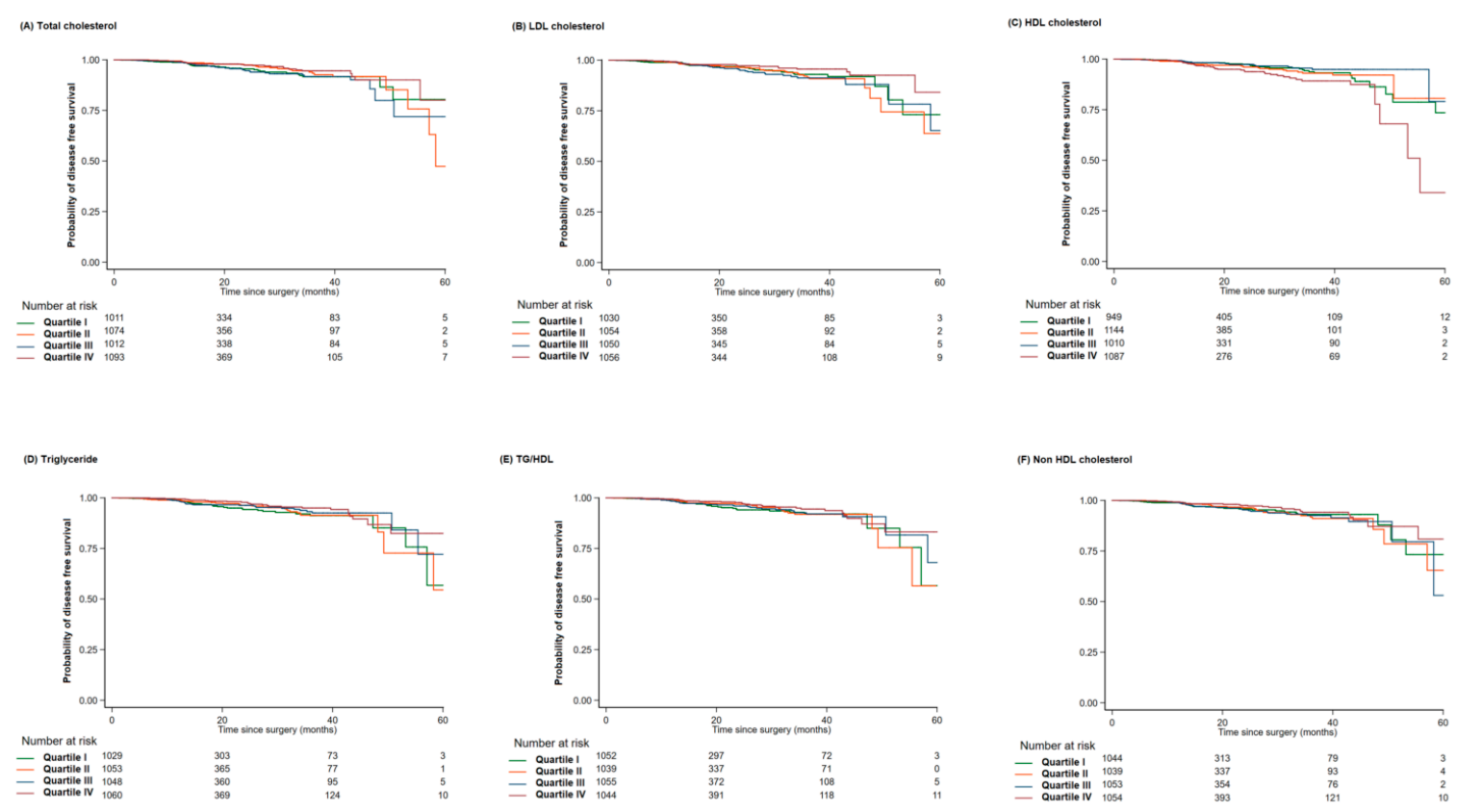

Figure 4. Hazard ratio by each lipid exam score. HDL: high density lipoprotein; LDL: low density lipoprotein; TG: total cholesterol. 


\section{Discussion}

In this study, breast cancer patients with a high level of bad lipids (LDL-C, TG, and TG/HDL) and low level of good lipid (HDL-C) showed good prognosis for cancer recurrence even though they had worse prognostic factors.

Cholesterol is an essential structural component of the cell membranes which helps maintain both membrane structural integrity and fluidity. Cholesterol is also implicated in cellular signaling pathways through assisting in the formation of lipid rafts in the plasma membrane, which brings receptor proteins in close proximity with high concentrations of second messenger molecules [12]. These key cellular signaling is closely associated with malignant transformation of cells because of their role in organization of the cytoskeleton, cell migration, and angiogenesis [12-14]. Another evidence is 27-Hydroxycholesterol (27HC) which is a primary metabolite of cholesterol bind to an ER and Liver X receptor (LXR), and increases ER-dependent growth and LXR-dependent metastasis in mouse models of breast cancer [37]. In addition to this, within cells, cholesterol also serves as a precursor for the biosynthesis of steroid hormones, including the sex hormones progesterone, estrogens, and their derivatives which is important risk factors in breast cancer development.

However, the role of serum lipid in breast cancer development and prognosis is controversial. A correlation between serum lipid and breast cancer development was reported in several studies: some authors have shown that the levels of TC and TG were elevated in breast cancer patients [15-18], and others reported that a high level of LDL or very low density lipoprotein (VLDL) [29] and low level of HDL-C $[21,25,26,31,32]$ are indicators of tumor development. Dyslipidemia is associated with overall breast cancer survival, and it has a role as prognostic factor for breast cancer [19]. However, there are also conflicting results. Some studies showed that no association between breast cancer risk and blood lipids was found [20-23], and others showed an inverse correlation between high serum lipid (TC [24], HDL [28,31], and TG [32]) and breast cancer development.

Although the role of serum lipids in the development of breast cancer has been relatively widely studied, there are few reports on their prognostic value. Laboratory investigations have shown that circulating levels of cholesterol, LDL-C, and HDL-C play a role in tumor development, growth, or aggressiveness and finally poor prognosis [19,38]. Bahl et al. [39] and Mousa et al. [40] showed a trend toward increased risk of recurrence with higher TC and LDL-C; however, another study reported that patients with hypercholesterolemia showed lower expression of endothelial vascular endothelial growth factor (VEGF) and basic fibroblast growth factor (bFGF) than patients with normocholesterolemia, and reducing blood cholesterol can suppress tumor growth by inhibiting tumor angiogenesis [41]. Studies on other types of cancer, not specifically breast cancer, have noted a relationship between low serum lipid and cancer morbidity and mortality [42,43].

Although there are still conflicting results about the serum lipid profile and breast cancer prognosis, in general breast cancer patients with high levels of TC, LDL-C, TG, and low level of HDL-C have been reported to show a poor prognosis of breast cancer, similar to the cardiovascular effects of lipid [19,38-40]. The inverse association that we observed between lipid profile and breast cancer recurrence appears to be discordant with previous reports. Our data indicated that desirable changes in lipid profile for cardiovascular disease risk are not always beneficial for breast cancer patients. Interestingly, patients with dyslipidemia (high bad cholesterol and low good cholesterol level) had worse prognostic factors of breast cancer (i.e., negative hormone receptor status, positive HER2 expression, higher nuclear grade). Even after adjusting for these poor prognostic factors, the patients showed good prognosis compared to patients with lower cholesterol levels. Among the variables in adjusted model, subtype (ER, PR, and HER2) is the factor which make change the significance. In breast cancer patients, IHC-defined subtypes showed different features, recurrence patterns, and survival [44].

There are several possible mechanisms underlying an inverse association between lipid profile and breast cancer recurrence. First, we could explain this result in terms of nutritional aspects. Serum lipid level is easily influenced by amount of food intake, and dietary pattern can also affect the lipid profile. A study that observed the effect of dietary patterns with respect to carbohydrate and 
fat content on blood lipid profiles in breast cancer patients showed that a low-fat diet resulted in a great reduction in TC and LDL-C, whereas a low-carbohydrate diet mainly influenced TG and HDL-C levels [45]. In addition, the serum lipid profile might be an indirect indicator of nutritional status $[46,47]$. Surprisingly, there are few studies on the role of poor nutritional status in prognosis of breast cancer. This is mainly because of the methodological difficulties in maintaining and applying lifestyle interventions to obtain direct evidence of a causal relationship in a randomized controlled trial. Although there is limited evidence suggesting that breast cancer prognosis is influenced by dietary fat intake and serum lipid level, indirect evidence is provided by observational studies with other indirect indicators such as BMI or lipid profile, which reflect the nutritional status. Obesity is a well-known risk factor and poor prognostic factor in breast cancer [9-11]. However, a large-scale study with Asian breast cancer patients reported that underweight was also associated with poorer survival $[48,49]$. The inclusion of undernourished patients in the lower lipid level group in our study, compared to the high lipid level group, may have partially contributed to the risk of recurrence.

Protective effects of serum lipid could also be explained by the indirect effects of statin usage. Although the data are controversial, there are several reports of the protective effects of statin usage in breast cancer patients [50-52]. We retrospectively searched past medical history and medication history and excluded patients who were diagnosed with dyslipidemia or using statins from our analysis. However, a complete enumeration survey was impossible because of the retrospective and single-institution study design. Many patients with dyslipidemia who were taking medicine in the local clinic rather than in our tertiary educational hospital could not be evaluated. In our study, $6 \%(521 / 8362)$ of patients were diagnosed with dyslipidemia. Compared to the generally accepted prevalence of approximately $20 \%$ [53,54], the prevalence of dyslipidemia in our study was extremely low. This implies that unrecognized dyslipidemia patients who were taking statins were probably included as normal patients in this analysis. In addition, even if all dyslipidemia patients were excluded in our analysis, the lipid levels analyzed in this study were baseline levels before surgery; therefore, the group of patients who showed good prognosis with dyslipidemia might have taken statins during the follow-up period. In such cases, the prognostic role of statin usage after breast cancer surgery will not be reflected in our results. This is a limitation of the cross-sectional study design.

There are other possible mechanisms to explain the good prognosis in patients with dyslipidemia. Ozdemir et al. [41] suggested that hypercholesterolemia impairs angiogenesis by suppressing endothelial and tumoral bFGF and VEGF expression. This could explain the good prognosis of hypercholesterolemia in our study. Other authors have suggested that hypocholesterolemia in cancer patients was caused by the breakdown of cholesterol by tumor cells expressing LDL receptor $[55,56]$. In this situation, the low level of serum lipid could be a reflection of tumor recurrence; therefore, these patients showed poor prognosis.

The strength of this study is its relatively large sample size. However, as already described, major limitations arise from the nature of the retrospective study design. For this reason, we could not obtain complete data on underlying disease such as diabetes and hypertension, which could influence the lipid profile, related diseases, and medication history. In addition, this was a cross-sectional study and therefore did not consider lipid profile changes during follow-up. We do not have any information regarding lipid marker at time of recurrence, therefore, our data did not account for the prognostic effects of lipid change and statin usage over time. Finally, our data were collected from one clinical institute and have limitations regarding generalization. It is necessary of further study regarding prognosis for the patients with recurrence considering importance and implication of patient with recurrence data.

\section{Conclusions}

Our study showed that baseline high lipid level could be a good prognostic factor of breast cancer. This indicated that desirable changes in lipid profile with respect to cardiovascular disease risk might 
not be beneficial for breast cancer patients. As proper control of lipid levels has advantages regarding cardiovascular disease, these data require careful interpretation.

Supplementary Materials: The following are available online at http://www.mdpi.com/2077-0383/9/9/2846/s1, Table S1: Characteristics by quartile of TC at baseline in breast cancer patients who underwent a surgery; Table S2: Characteristics by quartile of LDL at baseline in breast cancer patients who underwent a surgery; Table S3: Characteristics by quartile of HDL at baseline in breast cancer patients who underwent a surgery; Table S4: Characteristics by quartile of TG at baseline in breast cancer patients who underwent a surgery.

Author Contributions: S.K.L., S.J.N., and J.C. conceived and designed the study; D.K., and E.G. constructed the data; S.K.L., J.C., D.K., and E.G. analyzed the data; S.K.L., S.J.N., S.W.K., J.Y., and J.E.L. contributed reagents, materials, and/or analysis tools; S.M.J. and D.K wrote the manuscript; and J.C., J.E.L., and the E.G. made other contributions. All authors have read and agreed to the published version of the manuscript.

Funding: This research received no external funding.

Acknowledgments: This research was supported by Basic Science Research Program through the National Research Foundation of Korea (NRF) funded by the Ministry of Science, ICT and Future Planning (2017R1E1A1A0107764214).

Conflicts of Interest: The authors declare no conflict of interest.

\section{References}

1. Ferlay, J.; Soerjomataram, I.; Ervik, M.; Dikshit, R.; Eser, S.; Mathers, C.; Rebelo, M.; Parkin, D.M.; Forman, D.; Bray, F. GLOBOCAN 2012 v1.0, Cancer Incidence and Mortality Worldwide: IARC CancerBase No. 11; International Agency for Research on Cancer: Lyon, France, 2013.

2. Kohler, B.A.; Sherman, R.L.; Howlader, N.; Jemal, A.; Ryerson, A.B.; Henry, K.A.; Boscoe, F.P.; Cronin, K.A.; Lake, A.; Noone, A.M.; et al. Annual Report to the Nation on the Status of Cancer, 1975-2011, Featuring Incidence of Breast Cancer Subtypes by Race/Ethnicity, Poverty, and State. J. Natl. Cancer Inst. 2015, 107, djv048. [CrossRef] [PubMed]

3. Edwards, B.K.; Noone, A.M.; Mariotto, A.B.; Simard, E.P.; Boscoe, F.P.; Henley, S.J.; Jemal, A.; Cho, H.; Anderson, R.N.; Kohler, B.A.; et al. Annual Report to the Nation on the status of cancer, 1975-2010, featuring prevalence of comorbidity and impact on survival among persons with lung, colorectal, breast, or prostate cancer. Cancer 2014, 120, 1290-1314. [CrossRef] [PubMed]

4. Vuong, D.; Simpson, P.T.; Green, B.; Cummings, M.C.; Lakhani, S.R. Molecular classification of breast cancer. Virchows Arch. 2014, 465, 1-14. [CrossRef] [PubMed]

5. Smith-Warner, S.A.; Spiegelman, D.; Yaun, S.S.; van den Brandt, P.A.; Folsom, A.R.; Goldbohm, R.A.; Graham, S.; Holmberg, L.; Howe, G.R.; Marshall, J.R.; et al. Alcohol and breast cancer in women: A pooled analysis of cohort studies. JAMA 1998, 279, 535-540. [CrossRef]

6. Caan, B.J.; Natarajan, L.; Parker, B.; Gold, E.B.; Thomson, C.; Newman, V.; Rock, C.L.; Pu, M.; Al-Delaimy, W.; Pierce, J.P. Soy food consumption and breast cancer prognosis. Cancer Epidemiol. Prev. Biomark. 2011, 20, 854-858. [CrossRef]

7. Taylor, C.K.; Levy, R.M.; Elliott, J.C.; Burnett, B.P. The effect of genistein aglycone on cancer and cancer risk: A review of in vitro, preclinical, and clinical studies. Nutr. Rev. 2009, 67, 398-415. [CrossRef]

8. Reynolds, P.; Hurley, S.; Goldberg, D.E.; Anton-Culver, H.; Bernstein, L.; Deapen, D.; Horn-Ross, P.L.; Peel, D.; Pinder, R.; Ross, R.K.; et al. Active smoking, household passive smoking, and breast cancer: Evidence from the California Teachers Study. J. Natl. Cancer Inst. 2004, 96, 29-37. [CrossRef]

9. Chan, D.S.; Vieira, A.R.; Aune, D.; Bandera, E.V.; Greenwood, D.C.; McTiernan, A.; Navarro Rosenblatt, D.; Thune, I.; Vieira, R.; Norat, T. Body mass index and survival in women with breast cancer-systematic literature review and meta-analysis of 82 follow-up studies. Ann. Oncol. 2014, 25, 1901-1914. [CrossRef]

10. Protani, M.; Coory, M.; Martin, J.H. Effect of obesity on survival of women with breast cancer: Systematic review and meta-analysis. Breast Cancer Res. Treat. 2010, 123, 627-635. [CrossRef]

11. Dignam, J.J.; Wieand, K.; Johnson, K.A.; Fisher, B.; Xu, L.; Mamounas, E.P. Obesity, tamoxifen use, and outcomes in women with estrogen receptor-positive early-stage breast cancer. J. Natl. Cancer Inst. 2003, 95, 1467-1476. [CrossRef]

12. Lingwood, D.; Simons, K. Lipid rafts as a membrane-organizing principle. Science 2010, 327, 46-50. [CrossRef]

13. Murai, T. The role of lipid rafts in cancer cell adhesion and migration. Int. J. Cell Biol. 2012, 2012, 763283. [CrossRef] 
14. Incardona, J.P.; Eaton, S. Cholesterol in signal transduction. Curr. Opin. Cell Biol. 2000, 12, $193-203$. [CrossRef]

15. Yadav, N.K.; Poudel, B.; Thanpari, C.; Chandra Koner, B. Assessment of biochemical profiles in premenopausal and postmenopausal women with breast cancer. Asian Pac. J. Cancer Prev. 2012, 13, 3385-3388. [CrossRef] [PubMed]

16. Zielinski, C.C.; Stuller, I.; Rausch, P.; Muller, C. Increased serum concentrations of cholesterol and triglycerides in the progression of breast cancer. J. Cancer Res. Clin. Oncol. 1988, 114, 514-518. [CrossRef]

17. Owiredu, W.K.; Donkor, S.; Addai, B.W.; Amidu, N. Serum lipid profile of breast cancer patients. Pak. J. Biol. Sci. 2009, 12, 332-338. [CrossRef]

18. Wallace, R.B.; Rost, C.; Burmeister, L.F.; Pomrehn, P.R. Cancer incidence in humans: Relationship to plasma lipids and relative weight. J. Natl. Cancer Inst. 1982, 68, 915-918.

19. Emaus, A.; Veierod, M.B.; Tretli, S.; Finstad, S.E.; Selmer, R.; Furberg, A.S.; Bernstein, L.; Schlichting, E.; Thune, I. Metabolic profile, physical activity, and mortality in breast cancer patients. Breast Cancer Res. Treat. 2010, 121, 651-660. [CrossRef]

20. Ha, M.; Sung, J.; Song, Y.M. Serum $\mathrm{t}$ and the risk of breast cancer in postmenopausal Korean women. Cancer Causes Control 2009, 20, 1055-1060. [CrossRef]

21. Hoyer, A.P.; Engholm, G. Serum lipids and breast cancer risk: A cohort study of 5207 Danish women. Cancer Causes Control 1992, 3, 403-408. [CrossRef]

22. Hiatt, R.A.; Friedman, G.D.; Bawol, R.D.; Ury, H.K. Breast cancer and serum cholesterol. J. Natl. Cancer Inst. 1982, 68, 885-889. [PubMed]

23. Gaard, M.; Tretli, S.; Urdal, P. Risk of breast cancer in relation to blood lipids: A prospective study of 31,209 Norwegian women. Cancer Causes Control 1994, 5, 501-509. [CrossRef] [PubMed]

24. Vatten, L.J.; Foss, O.P. Total serum cholesterol and triglycerides and risk of breast cancer: A prospective study of 24,329 Norwegian women. Cancer Res. 1990, 50, 2341-2346.

25. Furberg, A.S.; Jasienska, G.; Bjurstam, N.; Torjesen, P.A.; Emaus, A.; Lipson, S.F.; Ellison, P.T.; Thune, I. Metabolic and hormonal profiles: HDL cholesterol as a plausible biomarker of breast cancer risk. The Norwegian EBBA Study. Cancer Epidemiol. Prev. Biomark. 2005, 14, 33-40.

26. Kucharska-Newton, A.M.; Rosamond, W.D.; Mink, P.J.; Alberg, A.J.; Shahar, E.; Folsom, A.R. HDL-cholesterol and incidence of breast cancer in the ARIC cohort study. Ann. Epidemiol. 2008, 18, 671-677. [CrossRef] [PubMed]

27. Ray, G.; Husain, S.A. Role of lipids, lipoproteins and vitamins in women with breast cancer. Clin. Biochem. 2001, 34, 71-76. [CrossRef]

28. Kim, Y.; Park, S.K.; Han, W.; Kim, D.H.; Hong, Y.C.; Ha, E.H.; Ahn, S.H.; Noh, D.Y.; Kang, D.; Yoo, K.Y. Serum high-density lipoprotein cholesterol and breast cancer risk by menopausal status, body mass index, and hormonal receptor in Korea. Cancer Epidemiol. Prev. Biomark. 2009, 18, 508-515. [CrossRef]

29. Chang, S.J.; Hou, M.F.; Tsai, S.M.; Wu, S.H.; Hou, L.A.; Ma, H.; Shann, T.Y.; Wu, S.H.; Tsai, L.Y. The association between lipid profiles and breast cancer among Taiwanese women. Clin. Chem. Lab. Med. 2007, 45, 1219-1223. [CrossRef] [PubMed]

30. Rosato, V.; Bosetti, C.; Talamini, R.; Levi, F.; Montella, M.; Giacosa, A.; Negri, E.; La Vecchia, C. Metabolic syndrome and the risk of breast cancer in postmenopausal women. Ann. Oncol. 2011, 22, 2687-2692. [CrossRef]

31. Ferraroni, M.; Gerber, M.; Decarli, A.; Richardson, S.; Marubini, E.; Crastes de Paulet, P.; Crastes de Paulet, A.; Pujol, H. HDL-cholesterol and breast cancer: A joint study in northern Italy and southern France. Int. J. Epidemiol. 1993, 22, 772-780. [CrossRef] [PubMed]

32. Ni, H.; Liu, H.; Gao, R. Serum Lipids and Breast Cancer Risk: A Meta-Analysis of Prospective Cohort Studies. PLoS ONE 2015, 10, e0142669. [CrossRef] [PubMed]

33. American Joint Committee on Cancer. Updated Breast Chapter for 8th Edition. Available online: https: //cancerstaging.org/references-tools/deskreferences/Pages/Breast-Cancer-Staging.aspx (accessed on 13 March 2018).

34. Harrell, F.E., Jr.; Lee, K.L.; Mark, D.B. Multivariable prognostic models: Issues in developing models, evaluating assumptions and adequacy, and measuring and reducing errors. Stat. Med. 1996, 15, 361-387. [CrossRef] 
35. Cordero, A.; Andres, E.; Ordonez, B.; Leon, M.; Laclaustra, M.; Grima, A.; Luengo, E.; Moreno, J.; Bes, M.; Pascual, I.; et al. Usefulness of triglycerides-to-high-density lipoprotein cholesterol ratio for predicting the first coronary event in men. Am. J. Cardiol. 2009, 104, 1393-1397. [CrossRef] [PubMed]

36. da Luz, P.L.; Favarato, D.; Faria-Neto, J.R., Jr.; Lemos, P.; Chagas, A.C. High ratio of triglycerides to HDL-cholesterol predicts extensive coronary disease. Clinics 2008, 63, 427-432. [CrossRef]

37. Nelson, E.R.; Wardell, S.E.; Jasper, J.S.; Park, S.; Suchindran, S.; Howe, M.K.; Carver, N.J.; Pillai, R.V.; Sullivan, P.M.; Sondhi, V.; et al. 27-Hydroxycholesterol links hypercholesterolemia and breast cancer pathophysiology. Science 2013, 342, 1094-1098. [CrossRef]

38. Llaverias, G.; Danilo, C.; Mercier, I.; Daumer, K.; Capozza, F.; Williams, T.M.; Sotgia, F.; Lisanti, M.P.; Frank, P.G. Role of cholesterol in the development and progression of breast cancer. Am. J. Pathol. 2011, 178, 402-412. [CrossRef]

39. Bahl, M.; Ennis, M.; Tannock, I.F.; Hux, J.E.; Pritchard, K.I.; Koo, J.; Goodwin, P.J. Serum lipids and outcome of early-stage breast cancer: Results of a prospective cohort study. Breast Cancer Res. Treat. 2005, 94, 135-144. [CrossRef]

40. Mousa, U.; Onur, H.; Utkan, G. Is obesity always a risk factor for all breast cancer patients? c-erbB2 expression is significantly lower in obese patients with early stage breast cancer. Clin. Transl. Oncol. 2012, 14, 923-930. [CrossRef]

41. Ozdemir, B.H.; Akcali, Z.; Haberal, M. Hypercholesterolemia impairs angiogenesis in patients with breast carcinoma and, therefore, lowers the risk of metastases. Am. J. Clin. Pathol. 2004, 122, 696-703. [CrossRef]

42. Sherwin, R.W.; Wentworth, D.N.; Cutler, J.A.; Hulley, S.B.; Kuller, L.H.; Stamler, J. Serum cholesterol levels and cancer mortality in 361,662 men screened for the Multiple Risk Factor Intervention Trial. JAMA 1987, 257, 943-948. [CrossRef]

43. Keys, A.; Aravanis, C.; Blackburn, H.; Buzina, R.; Dontas, A.S.; Fidanza, F.; Karvonen, M.J.; Menotti, A.; Nedeljkovic, S.; Punsar, S.; et al. Serum cholesterol and cancer mortality in the Seven Countries Study. Am. J. Epidemiol. 1985, 121, 870-883. [CrossRef] [PubMed]

44. Park, S.; Koo, J.S.; Kim, M.S.; Park, H.S.; Lee, J.S.; Lee, J.S.; Kim, S.I.; Park, B.W. Characteristics and outcomes according to molecular subtypes of breast cancer as classified by a panel of four biomarkers using immunohistochemistry. Breast 2012, 21, 50-57. [CrossRef] [PubMed]

45. Thompson, H.J.; Sedlacek, S.M.; Paul, D.; Wolfe, P.; McGinley, J.N.; Playdon, M.C.; Daeninck, E.A.; Bartels, S.N.; Wisthoff, M.R. Effect of dietary patterns differing in carbohydrate and fat content on blood lipid and glucose profiles based on weight-loss success of breast-cancer survivors. Breast Cancer Res. 2012, 14, R1. [CrossRef] [PubMed]

46. Itoh, K.; Imai, K.; Masuda, T.; Abe, S.; Nakao, H.; Tanaka, M.; Nakamura, M. Relationship between serum total cholesterol level and nutritional status in Japanese young female. Nutr. Res. 1999, 19, 1145-1152. [CrossRef]

47. Wang, J.; Hong, Z. Low Plasma Total Cholesterol Concentration: A Sensitive Evaluation Marker in Hospitalized Patients with Nutritional Deficiency Malnutrition. J. Food Nutr. Res. 2014, 2, 551-555. [CrossRef]

48. Kawai, M.; Tomotaki, A.; Miyata, H.; Iwamoto, T.; Niikura, N.; Anan, K.; Hayashi, N.; Aogi, K.; Ishida, T.; Masuoka, H.; et al. Body mass index and survival after diagnosis of invasive breast cancer: A study based on the Japanese National Clinical Database-Breast Cancer Registry. Cancer Med. 2016, 5, 1328-1340. [CrossRef]

49. Moon, H.G.; Han, W.; Noh, D.Y. Underweight and breast cancer recurrence and death: A report from the Korean Breast Cancer Society. J. Clin. Oncol. 2009, 27, 5899-5905. [CrossRef]

50. Ahern, T.P.; Pedersen, L.; Tarp, M.; Cronin-Fenton, D.P.; Garne, J.P.; Silliman, R.A.; Sorensen, H.T.; Lash, T.L. Statin prescriptions and breast cancer recurrence risk: A Danish nationwide prospective cohort study. J. Natl. Cancer Inst. 2011, 103, 1461-1468. [CrossRef]

51. Kwan, M.L.; Habel, L.A.; Flick, E.D.; Quesenberry, C.P.; Caan, B. Post-diagnosis statin use and breast cancer recurrence in a prospective cohort study of early stage breast cancer survivors. Breast Cancer Res. Treat. 2008, 109, 573-579. [CrossRef]

52. Harputluoglu, H.; Dizdar, O.; Karaahmet, F.; Altundag, K. Post-diagnosis statin use and breast recurrence sites in early stage breast cancer survivors. Breast Cancer Res. Treat. 2008, 110, 541. [CrossRef] 
53. Goff, D.C., Jr.; Bertoni, A.G.; Kramer, H.; Bonds, D.; Blumenthal, R.S.; Tsai, M.Y.; Psaty, B.M. Dyslipidemia prevalence, treatment, and control in the Multi-Ethnic Study of Atherosclerosis (MESA): Gender, ethnicity, and coronary artery calcium. Circulation 2006, 113, 647-656. [CrossRef] [PubMed]

54. Toth, P.P.; Potter, D.; Ming, E.E. Prevalence of lipid abnormalities in the United States: The National Health and Nutrition Examination Survey 2003-2006. J. Clin. Lipidol. 2012, 6, 325-330. [CrossRef] [PubMed]

55. Vitols, S.; Gahrton, G.; Ost, A.; Peterson, C. Elevated low density lipoprotein receptor activity in leukemic cells with monocytic differentiation. Blood 1984, 63, 1186-1193. [CrossRef] [PubMed]

56. Peterson, C.; Vitols, S.; Rudling, M.; Blomgren, H.; Edsmyr, F.; Skoog, L. Hypocholesterolemia in cancer patients may be caused by elevated LDL receptor activities in malignant cells. Med. Oncol. Tumor Pharmacother. 1985, 2, 143. [CrossRef]

(C) 2020 by the authors. Licensee MDPI, Basel, Switzerland. This article is an open access article distributed under the terms and conditions of the Creative Commons Attribution (CC BY) license (http://creativecommons.org/licenses/by/4.0/). 